\title{
Study on Stream Cooperation Connected Smart Manufacturing in Textile Timely Production System
}

\author{
Jae-Yong Lee ${ }^{1, a}$, Dae-Hee Lee ${ }^{1}$, Jae-Sung Song ${ }^{2}$, Jun-Hee Park ${ }^{3}$, Sung-Hun Ryu ${ }^{4}$, and Jeung-Hyun \\ Park $^{5}$ \\ ${ }^{1}$ Korea Textile Machinery Convergence Research Institute, Mechatronics Team, 38542 Gyeongbuk, South Korea \\ ${ }^{2}$ TNS Inc., CEO, 41026 Daegu, South Korea \\ ${ }^{3}$ Korea Apparel Intelligence Technology Institute, 13217 Gyeonggi, South Korea \\ ${ }^{4}$ YoungWoo Cnl Inc., 08380 Seoul, South Korea \\ ${ }^{5}$ Bogang Engineering Inc., 42709 Daegu, South Korea
}

\begin{abstract}
In general, the flow of detailed data through the physical sensing of the mechanical system and the analysis of the production process is important as well as the development of the CPS(cyber-physical system) system in smartizing the production plant. In this study, stream is composed of three main fields in order to make fabric factory as smart factory. The three streams are divided into a knitting process, a dyeing process, and a sewing process. It can be made into a system that can monitor and manage the fabric production process as an integrated system by connecting the three separated streams. Physical sensors are developed and applied to the textile machines used in the three streams, and software programs for collecting and delivering data was performed together to construct a system for data collection per stream.
\end{abstract}

\section{Introduction}

The world textile market size is 73.8 million tons in 2010, and the industrial scale is composed of clothing $>$ industrial $>$ life style. In order to accommodate the marketing strategies of the apparel companies and ensure the sustainability of the order receipt in such market conditions, it is necessary to construct a flexible production system that enables immediate production according to orders and a production system for collaboration between streams to cope with small orders and large orders. The major production methods of apparel industry in each country are changing from finished production business to CMT(cut, make, trim). Therefore, it is necessary to cooperate with each other in the stream because the fabric producers require accurate delivery time and quality. As apparel brands increase inventory control, reordering, small quantity, mass production, timely delivery, and planning management, programming development has been carried out in connection with the development of software for linkage between planning and design work of apparel brands. In this study, it is required to develop a smart manufacturing system that can exchange ICT-based inter-stream production formation because it requires a high-productivity collaboration system for timely production/delivery and flexible production of hit products.[1-2]

\footnotetext{
${ }^{\mathrm{a}}$ Corresponding author : jaeyonglee@hanmail.net
} 


\section{CPS in textile factory}

Detailed functional design of equipment and system for the development of high productivity cyberphysical system(CPS) for smart factory, and function concept setting per unit system wear carried out.[3-4]

\subsection{CPS system configuration}

\subsubsection{System Architecture}

The design of cyber-physical system architecture for the development of a smart manufacturing system is shown in Fig. 1.

\begin{tabular}{|c|c|c|c|c|c|c|c|c|}
\hline \multicolumn{2}{|c|}{ Applications } & \multicolumn{4}{|c|}{ Product simulator } & Process & \multirow{2}{*}{$\begin{array}{l}\text { Data } \\
\text { Interface }\end{array}$} & Device \\
\hline UX/UI & Report & \multirow{2}{*}{$\begin{array}{l}\text { Pattern } \\
\text { CAD }\end{array}$} & $\begin{array}{l}3 \mathrm{D} \\
\text { viewer }\end{array}$ & $\begin{array}{l}\text { Image } \\
\text { viewer }\end{array}$ & \multirow{2}{*}{$\begin{array}{l}\text { Textile } \\
\text { CAD }\end{array}$} & Scheduling & & $\begin{array}{c}\text { PC } \\
\text { (Tablet) }\end{array}$ \\
\hline $\mathrm{RFID}(\mathrm{QR})$ & Notice & & $\begin{array}{l}3 \mathrm{D} \\
\text { editor }\end{array}$ & $\begin{array}{l}\text { Image } \\
\text { converter }\end{array}$ & & Monitoring & Middleware & $\begin{array}{c}\text { loT } \\
\text { module }\end{array}$ \\
\hline API & Authority & \multicolumn{2}{|c|}{ Vector graphic engine } & \multicolumn{2}{|c|}{ Raster graphic engine } & Routing & Gateway & $\begin{array}{l}\text { Controller } \\
\text { (Device) }\end{array}$ \\
\hline \multicolumn{2}{|c|}{ Data management } & \multicolumn{5}{|c|}{ Data Libraries } & & \\
\hline Order & $\begin{array}{c}\text { Data } \\
\text { analysis }\end{array}$ & Common & History & $\begin{array}{l}\text { Product } \\
\text { configure }\end{array}$ & $\begin{array}{l}\text { Material } \\
\text { resource }\end{array}$ & $\begin{array}{l}\text { State } \\
\text { map }\end{array}$ & \multirow{2}{*}{ Data shell } & $\begin{array}{l}\text { Actuator } \\
\text { (Device) }\end{array}$ \\
\hline Delivery & Index & Asset & $\begin{array}{l}\text { Reference } \\
\text { (Dictionary) }\end{array}$ & $\begin{array}{l}\text { Tasking } \\
\text { (Recipe) }\end{array}$ & Inventory & Status & & $\begin{array}{l}\text { Sensor } \\
\text { (Device) }\end{array}$ \\
\hline \multicolumn{9}{|c|}{ Windows/Linux Kernel } \\
\hline \multicolumn{4}{|c|}{ Storage management } & \multicolumn{5}{|c|}{ External storage management } \\
\hline \multicolumn{2}{|c|}{ Database } & \multicolumn{2}{|c|}{$\begin{array}{l}\text { Library } \\
\text { Database }\end{array}$} & \multicolumn{2}{|c|}{$\begin{array}{c}\text { External } \\
\text { PDM/POP }\end{array}$} & ERP & & $\mathrm{SCM}$ \\
\hline
\end{tabular}

Figure 1. Architecture of CPS system configuration.

\subsubsection{Process Simulator-modeling}

The process of a smart factory is defined as a typical discrete event system (DES) because it consists of a number of resources (equipment, workers, work) and independent events (unit operations). Therefore, modelling is performed using Petri Net, which provides flexibility in finite resource modelling and model-based analytic performance evaluation among DES modelling tools.[5] Figure 2 shows the configuration sewing factory DES simulation.

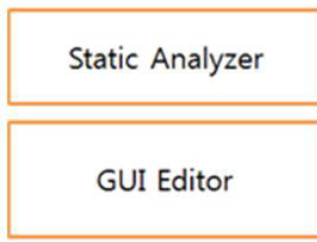

\section{Dynamic Analyzer}

Petri Net 5 Tuple Basic modeler(Open Source)

Figure 2. Sewing Factory DES Simulator. 


\subsubsection{Process Simulator-data packet}

The data structure of process simulator is made through process modelling using Petri Net model. The data packet consists of 4M (Man, Machine, Material, Method) data of individual process for management of manufacturing process. Figure 3 shows 2-way channel information configuration for CPS-based production management.

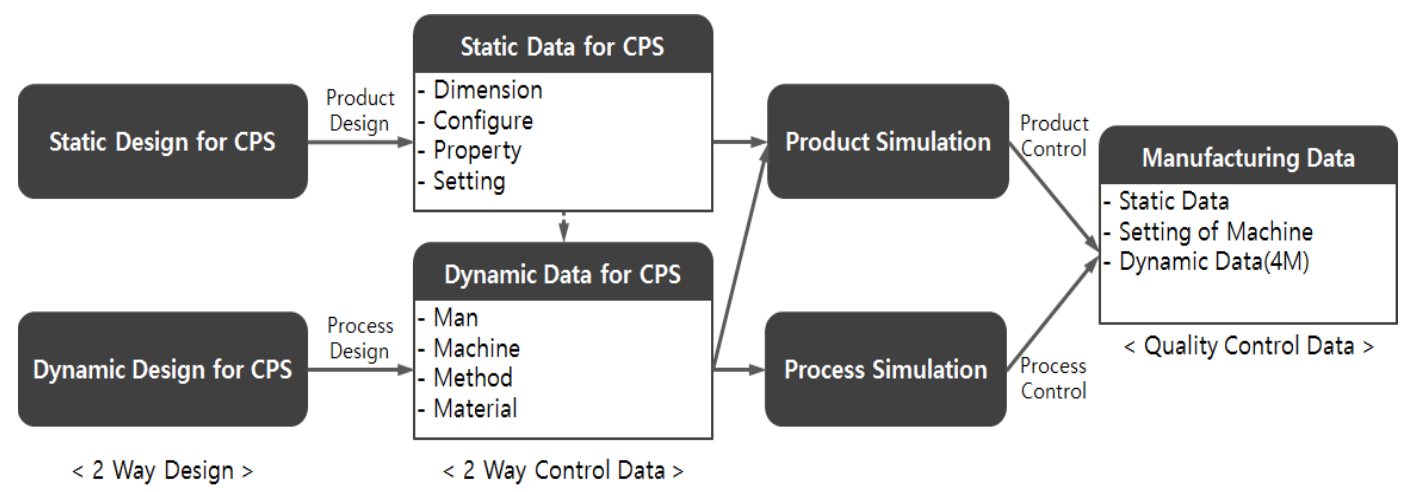

Figure 3. 2-way channel information configuration for CPS-based production management.

\subsection{Knitting / Dyeing / Apparel Stream}

The knitting / dyeing / apparel stream defines the sensor information detected in each machine, the respective machine status information, and the related information of the production fabric in association with the PDM through each POP terminal. Figure 4 shows three streams configuration of the connection through each configuration and data transfer.

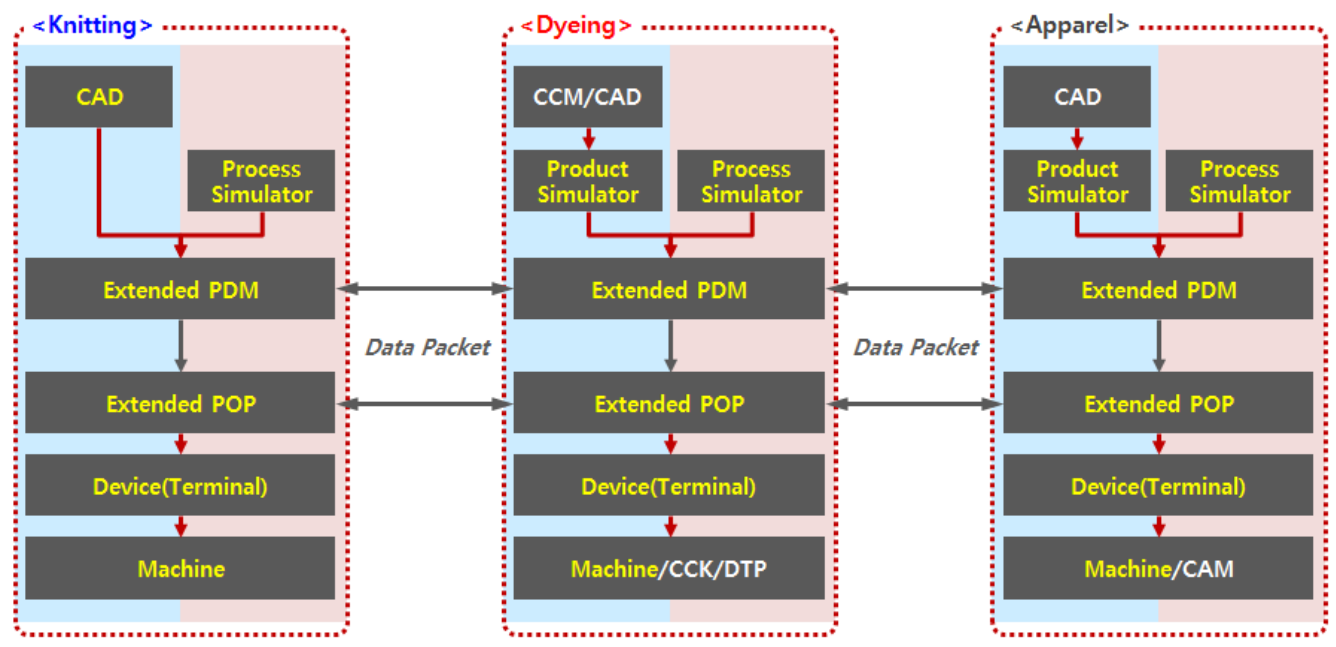

Figure 4. Three streams configuration of the connection through each configuration and data transfer.

\section{Machine sensor data transferring and software programming}


The smart process system was constructed by hardware parts sensor board and module development, communication and monitoring software programming of knitting machine in knitting stream. In dyeing stream, a software program for data collection was developed according to the dyeing process and a system for smart monitoring was constructed. In order to make the sewing machine smart in the apparel stream, the monitoring program and the system were constructed by the sensor development and application.[6]

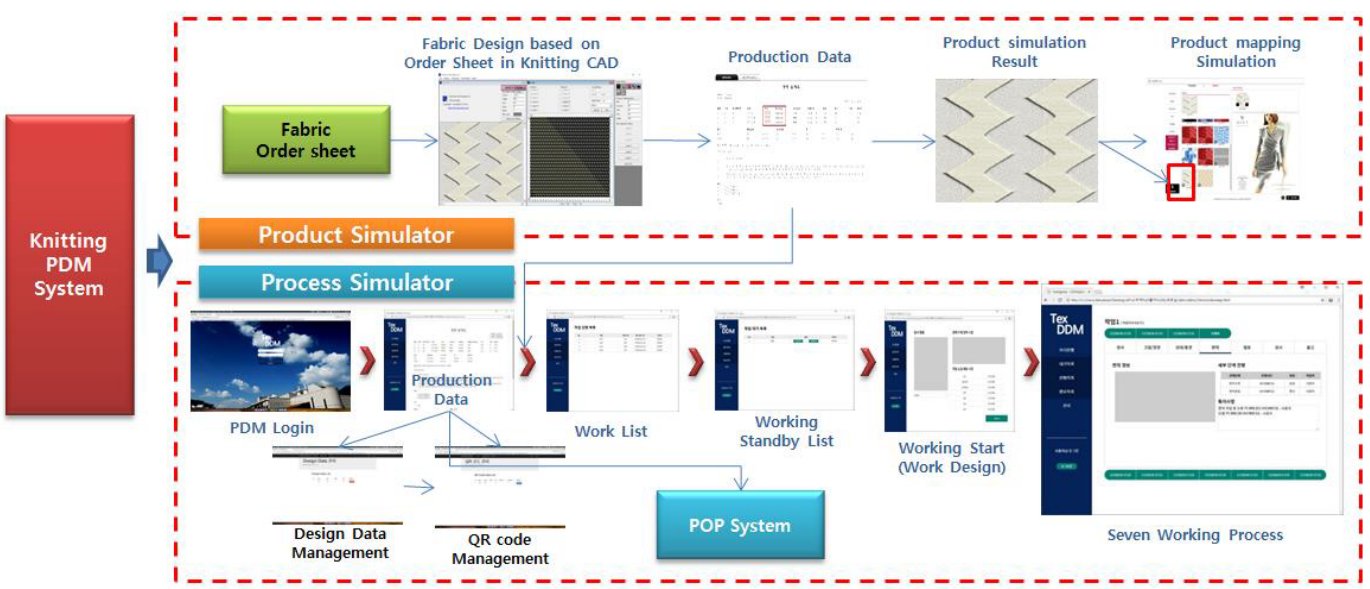

Figure 5. PDM function design and development in knitting stream.

Figure 5 shows the development of simulation technology using saved information after creating and storing knitting information (Meta Data) such as yarn information, bar information, and machine information based on seven bars in the knitting system.

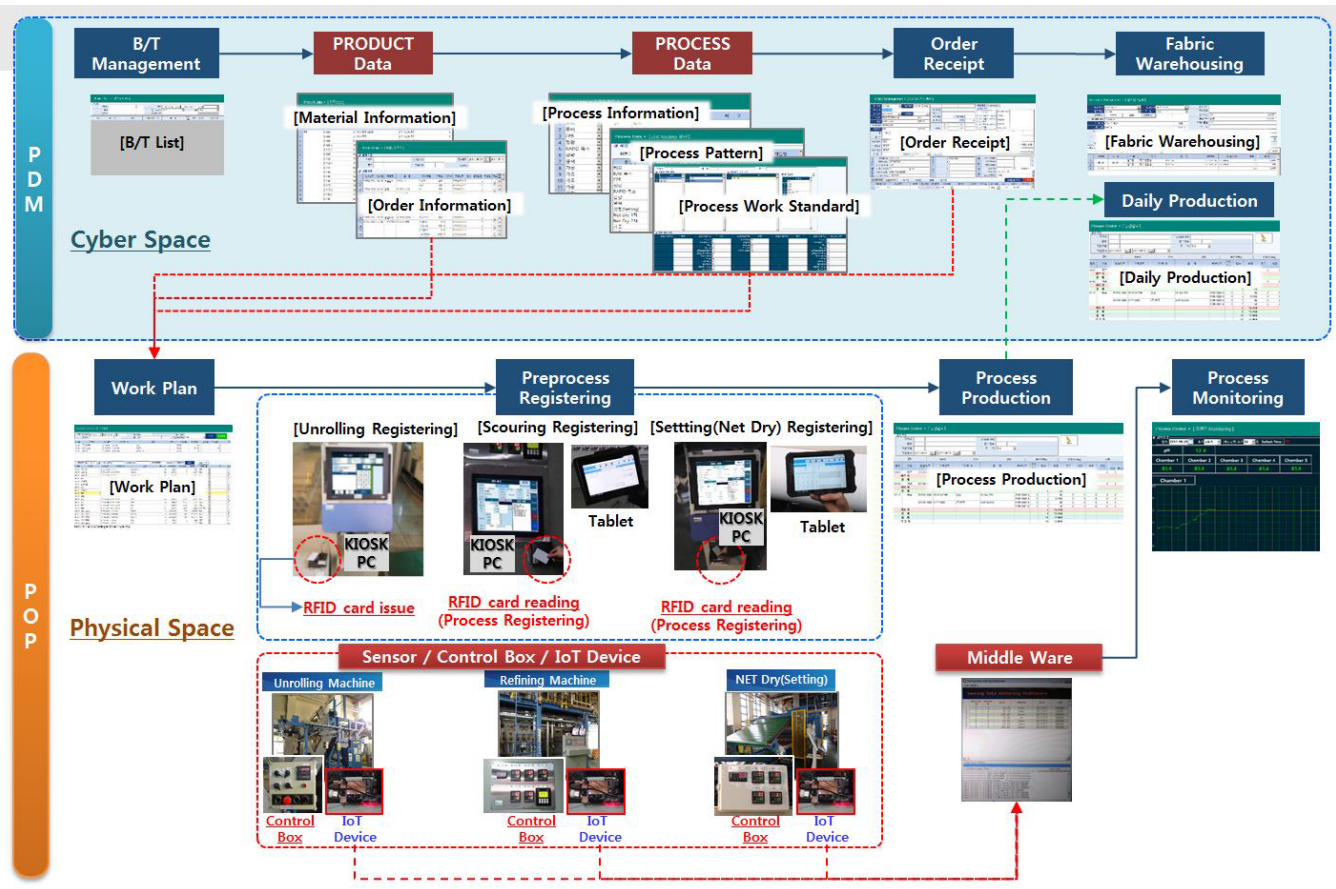

Figure 6. PDM and POP system design and development in dyeing stream. 
Figure 6 shows PDM and POP programming and system development to implement CPS in dyeing stream. In order to collect work performance information (process terminal/sensing) in the preprocessing process, the system collects actual data and plans for collecting work performance information by process through the POP system using the terminal, RFID card, and sensing data linking method in the field.

\section{[ Sewing Machine Data Monitoring ]}

1. Check the under-thread residual quantity

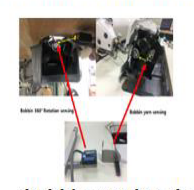

$<$ bobbin rotation check/ Under-thread sensing>
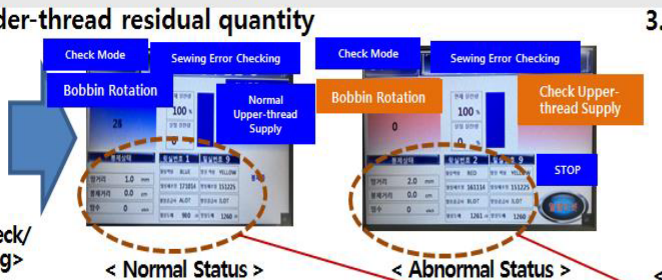

\section{Auto stitch control}

2. Check upper-thread existence

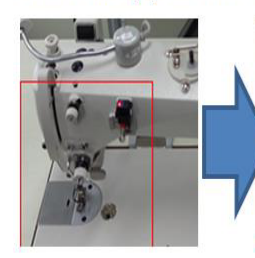

< Upper-thread Sensing >

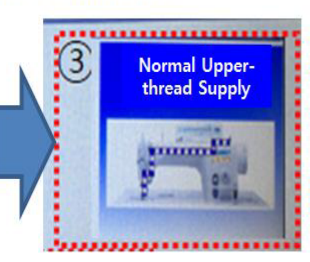

$<$ Normal Status >

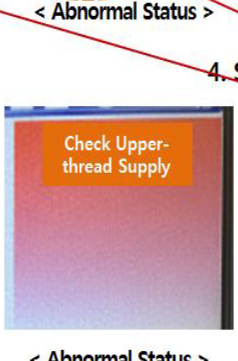

< Abnormal Status >

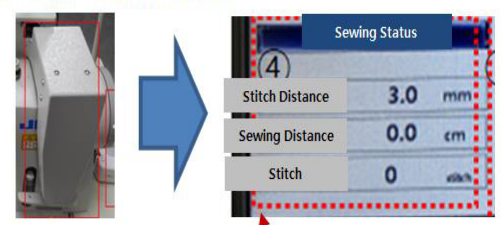

$<$ Stitch control>

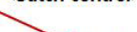

ing thread information(color, production date, etc)

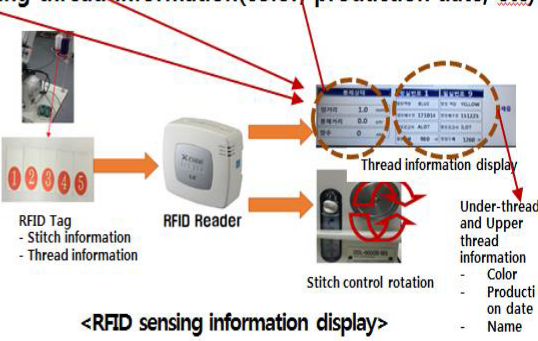

Figure 7. Sewing machine data monitoring and sensing system development in apparel stream.

In Figure 7, sensors such as laser sensor proximity sensor, and encoder were applied to collect mechanical information in the sewing machine to check the bobbin rotation state, under-thread volume, stitch number control and upper-thread supply status. The collected data is displayed on the monitor and transferred to the upper level POP and PDM to form an apparel stream.

\section{Conclusions}

In the textile industry, information integration and transmission among multiples streams is an important factor for smart factory applications. In addition, the current state of each machine and the process status of each stream should be applied to sensors and software programmed to collect data. In this study, we developed a system to apply smart factory in each stream by classifying streams into knitting, dyeing, and apparel fields. The smooth flow of data between streams is likely to transform the textile industry into a more innovative production environment.

The next study requires the development of a system that can manage all the streams from the apparel order to the finished product by monitoring each stream in the entire system by grouping the streams together.

\section{Acknowledgement}

This work was supported by the Ministry of Trade Industry and Energy (MOTIE). The project code is 10063057: Development of Textile Stream Connected Smart Manufacturing Innovation Technology by Timely Productive and Supplying for High Productive Textiles.

\section{References}


1. D. Lucke, C. Constantinescu and E. Westkamper, Smart Factory - A Step towards the Next Generation of Manufacturing, 115-118 (2008)

2. Rer.pol, Dipl.-Ing. Meike Tilebein, The new revolution in textiles and fashion manufacturing : Industry 4.0 and its implications, Creating a Smart Europe (2016)

3. L. Monostori, et al., Cyber-Physical systems in manufacturing, CIRP Annuals-Manufacturing Technology, 65, 621-641 (2016)

4. Dan Catalin, et al., Monitoring and Control Techniques of the installations on smart factory, Tehnomus, 364-368 (2013)

5. S.Y. Moon, et al., Simulation Modeling of Sewing Process for Evaluation of Production Schedule in Smart Factory, ICIMSA (2016)

6. J.Y. Lee, et al., Study on sensing and monitoring of sewing machine for textile stream smart manufacturing innovation, MMVP, 295-297 (2017) 